\title{
Políticas de educação profissional: referências e perspectivas
}

\section{Resumo}

$\bigcirc$ artigo revisita o processo histórico de construção do modelo de educação profissional de nível médio vigente no Brasil, procurando identificar aspectos que auxiliem na compreensão de questões pertinentes a essa modalidade de ensino. Aborda a dualidade do ensino médio, a associação entre discriminação social e ocupações técnicas, a contenção de demanda ao nível superior de ensino, a formação integral do cidadão e a formação para o mundo do trabaIho, situando a educação profissional na área da saúde nesse contexto. Foram utilizados, como fontes, a legislação brasileira para a educação, além de referenciais, diretrizes e documentos técnicos do Ministério da Educação. $\bigcirc$ artigo ressalta a importância que o conceito de terminalidade adquiriu nas propostas para a educação profissional, apontando a politecnia como alternativa

à formação escolar e profissional, assinalando as peculiaridades da área da saúde que a afastam do modelo de educação profissional de nível médio com caráter de terminalidade.

Palavras-chave: Educação profissional. Ensino técnico. Ensino médio. Terminalidade. Formação em saúde.

monicaw@fiocruz.br

Maria Helena Machado

Doutora em Sociologia

Pesquisadora da Fundação Oswaldo Cruz machado@ensp.fiocruz.br

\section{Antenor Amâncio Filho}

Doutor em Educação

Pesquisador da Fundação

Oswaldo Cruz

amancio@ensp.fiocruz.br

\section{Abstract Professional educational policies: references perspectives}

This paper argues the historical process of professional education models construction in the Brazilian high schools to help the understanding of this education modality questions. It approaches the high schools ambiguity, the association between social discrimination and technical occupations, containment of 
demand to the Universities, citizen's integral formation and formation to the work, pointing out the health area in this context. It had been used, as sources, the Brazilian legislation for the education and other governmental technical documents. The article intends to show the importance that the finish point concept acquired in the professional education proposals, pointing the politecnia as alternative to the school and professional formation, designating the peculiarities of the health area.

Keywords: Professional education. Technical education. High school. Health human resources.

\section{Resumen}

\section{Políticas de educación profesional: referencias $y$ perspectivas}

El artículo revisita el proceso histórico de la construcción del modelo de educación profesional del nivel medio en Brasil, buscando identificar los aspectos que ayuden a la comprensión de las cuestiones pertinentes a esta modalidad de educación. Aborda aspectos como la dualidad de la educación media, la asociación entre la discriminación social y las ocupaciones técnicas, la contención de la demanda a la universidad, la formación integral del ciudadano y la formación para el mundo del trabajo, precisando la educación profesional en el área de la salud en este contexto. Han sido utilizados, como fuentes, la legislación brasileña para la educación, además de los referenciales, las directrices y documentos técnicos del ministerio de la educación. El artículo resalta la importancia que el concepto de término de formación adquirió en las propuestas para la educación profesional, señalando la politecnia como alternativa a la formación propedéutica y profesional, señalando las particularidades del área de la salud que la separan del modelo de la educación profesional de nivel medio con carácter de término de formación.

Palabras clave: Educación profesional. Educación técnica. Escuela secundaria. Recursos humanos de la salud.

\section{Introdução}

No Brasil, quando se discute educação, é preciso considerar inúmeros aspectos, pelo fato de ser este um país de dimensões continentais, com situações sociais, econômicas e culturais típicas e diferenciadas, que obrigam a refletir sobre como se aproximam e se articulam as ações promovidas nas três esferas de governo (municipal, estadual e federal), bem como se essas ações refletem os anseios da população no que diz respeito à escolaridade e à formação para o trabalho.

Historicamente, apesar dos esforços empreendidos para estabelecer políticas educacionais afirmativas dessa modalidade de ensino, a educação profissional de nível médio foi e continua sendo discriminada por uma significativa parcela da sociedade, que a tem como um meio de fazer ingressar no mercado de trabalho pessoas consideradas como possuidoras de capacidade intelectual, econômica e social insuficientes para prosseguirem nos estudos. A baixa definição dos objetivos, finalidades e proposições dessa modalidade de ensino, certamente podem ser tomados como fatores contributivos para esse entendimento. 
Também não se pode perder de vista que a delimitação do trabalho dos técnicos depende de situações locais e de circunstâncias que os tornam profissionais necessários e fundamentais no campo em que atuam. Quando se trata de um laboratório, por exemplo, os técnicos executam ensaios experimentais e suas ponderações e interpretações constituem fontes de informação para que os pesquisadores avaliem os resultados obtidos e as estratégias adotadas. Se, no entanto, o trabalho ocorre em uma unidade de saúde, as relações e interações que se estabelecem nesse espaço diferem das que ocorrem em um laboratório, pois nele há um componente central do processo de trabalho, que é o doente, ou seja, as relações incluem o doente e as inúmeras implicações que disso advém.

Em virtude das especificidades e peculiaridades que caracterizam o trabalho em saúde (preservação da existência humana, luta constante pela manutenção da vida, cuidados para evitar riscos à saúde e à qualidade de vida do ser humano, convívio e oposição permanente ao fenômeno morte), a formação de recursos humanos para o setor constitui-se em locus privilegiado de estudo das variáveis - políticas, econômicas, sociais e culturais - que permeiam a educação profissional de nível médio em nosso país.

Em uma sociedade estratificada e hierarquizada como a nossa, a aplicabilidade tanto do conceito de saúde expresso na $8^{a}$. Conferência Nacional de Saúde quanto da noção de saúde como direito social, esbarra em limitações e obstáculos, especialmente se considerarmos que as desigualdades sociais e regionais existentes refletem condições estruturais que restringem o desenvolvimento de um nível satisfatório de saúde e de uma or- ganização de serviços socialmente adequados. Portanto, a formação de pessoal técnico de nível médio da saúde deve fundamentarse em uma visão crítica do contexto social, não dissociando o domínio da técnica da participação e do agir político.

A constituição e a implementação do Sistema Único de Saúde, trouxe novos cenários e possibilidades que exigem estratégias de formação que tenham como referência os princípios éticos da universalidade, da equidade e da integralidade, visando a garantir à população o acesso igualitário às ações e serviços para a promoção, proteção e recuperação da saúde.

Fundamental, ainda, é compreender a vital importância de recursos humanos bem formados e comprometidos com a causa da saúde para garantir a qualidade e a resolubilidade dos cuidados e dos serviços de saúde disponíveis para a população. Nesse contexto, as relações entre educação e trabalho assumem posições estratégicas e repletas de novos significados, pois

a função da educação se torna mais importante na preparação da força de trabalho, uma vez que as habilidades requeridas do novo trabalhador são muito relacionadas com aquelas desenvolvidas na escola, isto é, responsabilidade, capacidade de abstração, de resolver problemas, de trabalhar com símbolos e compreensão de textos abstratos, entre outras. (SALGADO, 1997, p. 87).

presente artigo foi construído na percepção de que o processo de mudança deve conjugar clareza e vontade política, compromisso social e competência técnica, remetendo à reflexão sobre o processo de educar cidadãos para a vida e para o mundo do trabalho. 


\section{Ensino médio: formar para a universidade ou para o trabalho?}

De uma maneira geral, o ensino de nível médio manteve, durante décadas, a finalidade de preparar o aluno para ingressar no ensino superior. Já na década de trinta do século passado, esse aspecto propedêutico era ressaltado de modo enfático por Campos (1931, p. 3): "O ensino secundário tem sido considerado entre nós como um simples instrumento de preparação dos candidatos ao ensino superior, desprezando-se, assim, a sua função eminentemente educativa."

Ao longo do tempo, a ausência de uma política educacional que articulasse o mundo escolar com o mundo do trabalho acabou por delegar ao ensino secundário o caráter de transição entre os níveis de ensino fundamental e superior. Como tentativa de resposta a essa aparente falta de objetividade da educação intermediária, em 1971 foi sancionada a Lei $n^{\circ} 5.692$ (BRASIL, 1971), visando a tornar compulsória a profissionalização mediante um intenso processo de qualificação para o trabalho. Os currículos passaram a ter um núcleo comum obrigatório, de alcance nacional, com enfoque na educação geral e uma parte diversificada, para atender às especificidades locais mediante a habilitação profissional dos alunos.

$\mathrm{Na}$ busca da interação entre o ensino propedêutico e o técnico, a Lei preconizava a preparação para o trabalho, de acordo com as necessidades do mercado, em consonância com uma formação geral que objetivava fornecer ao aluno condições para desenvolver suas potencialidades, alcançar sua auto-realização e exercitar, de forma consciente, seu direito de cidadania. Nessa perspectiva, segundo Sucupira (1974, p.13):

A cultura geral se faz necessária para servir de base à educação profissional não somente pelos conhecimentos que oferece, mas também pelas qualidades intelectuais que desenvolve. Ao mesmo tempo, a formação profissional aparece como elemento da personalidade humana integral, como elemento da própria cultura. A formação profissional e a própria profissão constituem fator educativo, fator de socialização do indivíduo, modo de afirmação e aperfeiçoamento do homem. Há, portanto, complementaridade entre educação geral e formação profissional.

Em que pese a intenção manifesta, equacionar as duas formas de ensino trouxe incontáveis transtornos de ordem prática, tendo-se tornado freqüentes as polêmicas e os debates em torno do tema "tecnologia versus humanismo". Problemas e dificuldades surgiram para a implantação do novo modelo educativo, cuja explicação pode ser encontrada em diversas razões, como o viés acadêmico de que se revestiu a proposta, a falta de esclarecimento dos professores em relação ao projeto, a falta de incentivo para adoção e aplicação das novas diretrizes e a carência de professores qualificados para ministrarem disciplinas novas (OLIVEIRA, 1981, p.133-134). Podese acrescentar a esses fatores a falta de apoio ao modelo por parte da sociedade, que continuava a compreender o ensino secundário como uma etapa preparatória para a universidade. Nesse contexto, a generalização do ensino profissional no nível médio não se concretizou, extinguindo-se sua obrigatoriedade e restabelecendo-se a mo- 
dalidade de educação geral pela promulgação da Lei nº 7.044 (BRASIL, 1982), que, a rigor, apenas referendou o que já vinha sendo praticado nas escolas, reafirmando a concepção do ensino médio como uma modalidade destinada aos já socialmente incluídos nos benefícios da produção e do consumo, preparando-os para ingressar na universidade (KUENZER, 2001, p. 30).

Segundo Machado (1989, p. 33), distorções ainda prevalecem no ensino de nível médio, em especial pelo fato de que O ensino médio fica como uma espécie de nó, no centro da contradição: é profissionalizante, mas não é; é propedêutico, mas não é. Constitui, portanto, o problema nevrálgico das reformas de ensino que revela em maior medida, o caráter de abertura ou de restrição do sistema educacional de cada nação. Não existe clareza a respeito dos seus objetivos e métodos e geralmente costuma ser o último nível de ensino a ser organizado.

Frente a essa realidade complexa, é necessário refletir sobre uma proposta pedagógica que contenha, em seus pressupostos teóricos, elementos que atendam às condições dessa mesma realidade. Com essa compreensão, pode ser pensada uma proposta para o ensino médio "à luz do trabalho tomado como princípio educativo" (KUENZER, 1989 , p. 31), formulada sob o conceito de uma organização de ensino que conjugue três características: que seja politécnica quanto ao conteúdo, única quanto à estrutura e dialética quanto à metodologia.

Enquanto as características provenientes da escola unitária e da relação dialética conduzem ao desenvolvimento do raciocínio crítico e histórico do ser humano, o conceito de politecnia pressupõe ultrapassar o conhecimento meramente empírico e requer formas de pensamento mais abstratas. Isso significa ir além da formação técnica e enseja um trabalhador com perfil mais amplo, "consciente, capaz de atuar criticamente em atividades de caráter criador e de buscar com autonomia os conhecimentos necessários ao seu progressivo aperfeiçoamento." (MACHADO, 1989, p. 19).

Do ponto de vista pedagógico, a noção de politecnia encaminha para a superação da distinção entre trabalho manual e trabalho intelectual, entre instrução profissional e instrução geral. Ou seja, aprender a ler, escrever e contar, além de noções cognitivas das ciências naturais e das ciências sociais, são pressupostos básicos para compreender o mundo em que se vive, inclusive para compreender a própria incorporação, pelo trabalho, dos conhecimentos científicos, no contexto da vida e da sociedade (SAVIANI, 2003, p. 140). Por essa perspectiva, politecnia diz respeito ao domínio dos fundamentos científicos das diferentes técnicas que caracterizam o processo de trabalho produtivo moderno. Está relacionada aos fundamentos das diferentes modalidades de trabalho e tem como base determinados princípios, determinados fundamentos, que devem ser garantidos pela formação politécnica.

Calcada nesse entendimento, a educação politécnica permitiria propiciar ao trabalhador a formação centrada no desenvolvimento multidimensional, capaz de habilitá-lo para o exercício de diversificadas funções, rejeitando adestramentos direcionados para tarefas específicas. Articular o trabalho manual e intelectual durante o 
processo de formação é uma forma eficiente e eficaz de aprendizagem, que possibilita assimilar, unindo teoria e prática, os princípios científicos preconizados na organização do processo produtivo.

Se é verdade que a concepção original dos cursos técnicos integrados, oferecidos por escolas técnicas e Centros Federais de Educação Tecnológica - CEFETs, se vinculava a orientações tecnicistas,

ainda assim as diversas possibilidades de integração de conteúdos da teoria e a infra-estrutura disponível na maioria dessas instituições, fez com que esses cursos viessem a constituir, na prática, a experiência na história da educação brasileira que mais se aproximou de uma formação integral no nível médio, embrião do que poderia aproximar-se da concepção politécnica em construção. (GARCIA; LIMA FILHO, 2004, p. 23)

Por sua vez, pode-se compreender que a utilização do conceito de polivalência nos documentos empresariais elaborados e divulgados por empresas como tentativa de fazer do processo educativo um espaço de formação de indivíduos que se identifiquem diretamente com os interesses (como se esses também fossem seus) dos setores empresariais. A ênfase em flexibilidade e competências nas diretrizes da educação profissional estariam, assim, atendendo de forma subjacente aos interesses dos setores produtivos. Por esse enfoque, a utilização do conceito de polivalência se apresentaria como mais uma expressão da modificação do discurso das elites visando conseguir, também no plano da produção, a sua hegemonia política. A utilização do conceito de polivalência procura criar a falsa impressão de que as tarefas realiza- das pelos trabalhadores na produção flexível requerem um conjunto maior de qualificação. Na prática, o que se estabelece é a exigência que os trabalhadores sejam multifuncionais. (OLIVEIRA, 2003, p. 259).

\section{Educação profissional: um dilema histórico}

A educação profissional, em nosso país, pode ser compreendida como um sistema que reflete determinada visão de mundo, mas que denota uma limitada apreensão da realidade, se considerada a delimitação tempo-espaço e as especificidades que nele ocorrem. É possível, porém, quantificar e qualificar os princípios informativos da lógica desse sistema educativo, que assume configurações definidas em cada momento histórico, numa espécie de ambiência, equivalente a um contínuo processo de mutação.

Aceita essa perspectiva, apreende-se que as primeiras iniciativas, no sentido de firmar uma relação entre educação e trabalho, foram realizadas em virtude do desenvolvimento da economia de subsistência e, particularmente, do incremento à atividade extrativa de minérios em Minas Gerais. Os primeiros núcleos de formação profissional de artesãos e demais ofícios, as "escolas-oficina", foram sediadas nos colégios e residências dos padres jesuítas. A Companhia de Jesus trouxe da Europa religiosos para aqui praticarem suas especialidades profissionais e, simultaneamente, ensinarem seus misteres a escravos e homens livres que demonstrassem habilidades para a aprendizagem. Visavam, desse modo, suprir a carência de mão-de-obra especializada observada na Colônia. (MANFREDI, 2002, p. 69). 
A par da atividade educativa e da catequese dos indígenas, os jesuítas tiveram influência decisiva na construção de escolas para setores da elite do Brasil Colônia. Tal como havia ocorrido em Portugal, os colégios jesuítas se dedicavam, sobretudo, à formação de indivíduos para ocupar posições de direção e de mando na sociedade, privilegiando o currículo humanístico, que mais interessava às famílias dos ricos senhores de engenho, por assemelhar-se à cultura dos nobres portugueses. Por conseqüência, o ensino científico profissional pouco evoluía por estar associado ao trabalho manual, tido como próprio para os escravos. O próprio sistema escravocrata vigente à época imprimia um caráter subalterno às atividades físicas e manuais. Assim,

numa sociedade onde o trabalho manual era destinado aos escravos (índios e africanos), essa característica 'contaminava' todas as atividades que lhes eram destinadas, as que exigiam esforço físico ou a utilização das mãos [...]. Aí está a base do preconceito contra o trabalho manual, inclusive e principalmente daqueles que estavam socialmente mais próximos dos escravos: mestiços e brancos pobres. (CUNHA, 2000, p. 90).

Com a transferência da Corte Portuguesa para o Brasil, em 1808, ocorrem transformações sociais, econômicas e políticas de grande significado para a Colônia. Do ponto de vista da educação profissional, a historiografia oficial aponta a formação de corporações de ofícios, a exemplo de Portugal, onde foram adotados os padrões de hierarquia e disciplina vigentes no âmbito militar. Tais instituições, criadas e mantidas por sociedades particulares, com apoio do Esta- do, representam "o marco inicial da organização do trabalho no País, e da aprendizagem, embora assistemática, de artífices naturais da terra" (FONTES, 1985, p. 14). É importante ressaltar que as características principais desses estabelecimentos de aprendizagem eram seu aspecto assistencialista de atendimento aos órfãos e desvalidos e sua recusa em ensinar a negros e escravos. Eram vistas mais como "obras de caridade" do que como "obras de instrução pública". (MANFREDI, 2002, p. 77).

A título ilustrativo, cabe mencionar que, na cidade do Rio de Janeiro, a educação profissional surgiu sob o argumento de promover a inclusão social de uma parcela da população que não tinha acesso ao mercado de trabalho. Com essa mentalidade foi criada, no final da década de 1890, a Escola Correcional, no Bairro de São Cristóvão, que se destinava a ensinar algum ofício "a meninos pobres e desvalidos da fortuna". Mediante o preparo profissional desses meninos, atendia-se à demanda do crescimento desordenado da população, em uma época de profundas transformações urbanísticas que ocorriam na cidade.

Durante a Primeira República (18891929), a educação profissional ganhou nova configuração sem, contudo, perder o caráter assistencialista. Nessa época, foram criadas, pelo Presidente Nilo Peçanha', nas capitais dos estados, escolas de aprendizes e artífices para o ensino profissional gratuito, considerando que

O aumento constante da população das cidades exigia que se facilitasse às classes proletárias os meios de vencer as dificuldades sempre crescentes na luta

1 Presidente da República (1909-1910), assumiu o cargo em decorrência da morte do Presidente Afonso Pena. 
pela existência e que, para isso, se tornava necessário, não só habilitar os fiIhos dos desfavorecidos da fortuna com o indispensável preparo técnico e intelectual, como fazê-los adquirir hábitos de trabalho profícuo que os afastassem da ociosidade, da escola do vício e do crime. (BRASIL, 1909).

Os aspectos de cunho social e caritativo marcaram indelevelmente os primórdios da educação técnica no Brasil. Sempre esteve associada à população de baixa renda, sem identidade, destituída de intenções pedagógicas de desenvolvimento intelectual pleno: "O governo e os industriais viam as escolas como instituições piedosas e não integradas à estrutura de produção, além dos aspectos limitados impostos à qualificação qualitativa mais ampla da mão-deobra industrial". (FONTES, 1985, p. 24).

Até a década de 30, o Brasil era um país agroexportador, tendo como base econômica a indústria açucareira e, posteriormente, a do café. As forças políticas sustentavam as oligarquias rurais, um dos principais pontos de apoio da classe dominante. A estrutura social, de sólida formação econômica, reduzia a importância do papel do Estado, que freqüentemente não detinha a força política necessária para promover intervenções nas unidades federadas. Nesse cenário, predominava uma concepção de ensino elitista, voltada para a área de letras e humanidades. As esparsas tentativas para dar ao ensino profissional um tratamento sistematizado e caráter de obrigatoriedade, não obtiveram sucesso, dentre outras razões pelo fato de que, em uma economia essencialmente agroexportadora, à população trabalhadora era suficiente um nível de escolaridade baixo.
Assim, a política educacional brasileira no primeiro quarto do Século XX

acaba por admitir que, afinal, o Brasil é ainda um imenso território a ser explorado, que muitas mercadorias estão lá, praticamente prontas, dadas, nos pastos, nas florestas, nas águas, nas abundantes e férteis terras. Ora, essas mercadorias precisam apenas de braços fortes e musculosos, de puras energias humanas e de elementares instrumentos técnicos que simplesmente as extraiam, 'limpando-as do cascalho', cortando, colhendo, pescando. (NOSELLA, 2002, p. 168).

Com o lançamento, na década de 30, de um projeto industrial para o país, a educação profissional sofreu significativas modificações, aumentando a demanda para a formação de operários especializados e de quadros técnicos intermediários. Como desdobramento, a Constituição de 1937 estabeleceu a obrigatoriedade da organização de escolas de aprendizes, por parte de empresas e de sindicatos. Mérito inquestionável dessa Constituição foi eliminar a referência que se fazia, sempre, ao ensino profissionalizante como destinado aos desfavorecidos da fortuna ou desvalidos da sorte. No período do Estado Novo (19371945), o governo adotou o ensino profissional como prioridade, visando a formar trabalhadores capazes de se adequarem à organização científica do trabalho, princípio que se ajustava à inspiração tayloristafordista de organização do trabalho na produção industrial (KIRSCHNER, 1993, p. 14).

Na década de 40, no plano das reformas educacionais, busca-se a adesão dos industriais para a manutenção de cursos profissionais para os operários. Promulga-se um de- 
creto determinando que os cursos poderiam ser instalados, como unidades autônomas, nas indústrias ou em suas proximidades, podendo ser mantidos em comum por vários estabelecimentos industriais. Duas outras iniciativas importantes ocorrem em 1942, contribuindo para a adequação da formação profissional às tendências de parcialização do processo de trabalho: foi criado o Serviço Nacional da Aprendizagem -SENAI, que liberou as indústrias e sindicatos da responsabilidade exclusiva da educação profissional de seus operários e promulgada a Lei Orgânica do Ensino Industrial que, além de estabelecer as bases da organização desse ensino, equiparou-o ao ensino secundário e introduziu a orientação educacional nas escolas de formação profissional.

A década de 50 teve o mérito de promover, por meio de inúmeros atos legais, o ajuste e a reformulação da estrutura educacional erigida durante o período autoritário do Estado Novo. Quando a Lei de Diretrizes e Bases da Educação, Lei nº. 4.024 (BRASIL, 1961), foi finalmente promulgada, muitas das inovações nela constantes já tinham sido incorporadas ao cotidiano educacional, como, por exemplo, a equivalência entre os diversos ramos de ensino médio e a legislação sobre cursos em cooperação com empresas.

No início da década de 60, acentua-se a internacionalização da economia, com forte participação do Estado, que passou a ocupar posição central no processo de moder- nização. Teve início o Plano de Metas do governo Kubitschek (1956-1961), que continha trinta propostas (com ênfase nos setores de energia, transporte, siderurgia, cimento, automobilística, naval), que contribuiriam para mudar a feição do país, fazendo com que deixasse de ser uma nação agrária para se tornar um país industrial, com a formação técnico-profissional passando a ser sinônimo de modernização. A transformação político-institucional, em 1964, acentuou, ainda mais, a tendência de racionalidade via concepção tecnicista da educação².

Para completar o ciclo de iniciativas do período denominado de "tendência tecnicista", o Congresso Nacional aprova e o Governo promulga, em 1971, a Lei n 5.692 (BRASIL, 1971), que institui o ensino de segundo grau de profissionalização compulsória. A principal justificativa dos que defendiam a generalização da formação profissional nesse nível de ensino era uma suposta demanda do mercado de trabalho por técnicos de nível médio, surgida em decorrência do crescimento econômico acelerado do período denominado de "milagre econômico", entre os anos de 1968 e 1974 (LIMA, 1996, p. 33). Entretanto, seja pela falta de estrutura para implantação de cursos técnicos ou pela falta de pessoal docente habilitado para lecionar nesses cursos, essa medida nunca chegou a ser amplamente adotada, sendo alvo de inúmeras críicas e de fortes controvérsias a tal ponto que, alguns anos depois, o governo editou outro instrumento legal, eliminando o caráter compulsório da profissionalização.

\footnotetext{
2 Surgiram, nessa época, várias iniciativas no campo da educação profissionalizante: Ginásios industriais (1961); Ginásios orientados para o trabalho (1963); Programa Intensivo de Preparação de Mão-de-Obra Industrial (1963); Centro de Educação Técnica, no Rio de Janeiro e em São Paulo (1964);Fundação de Educação para o Trabalho de Minas Gerais (1965); Centro de Educação Técnica do Nordeste (1967); Centro de Educação Técnica da Amazônia (1968); Centro de Educação Técnica de Brasília (1968); Centro de Educação Técnica da Bahia (1968); Programa de Expansão e Melhoria do Ensino Médio (1968); Centro Estadual de Educação Tecnológica Paula Souza (1969); Fundação Centro Nacional de Aperfeiçoamento de Pessoal para a Formação Profissional (1969). (KIRSCHNER, 1993, p. 12).
} 
desenvolvimento industrial do país e a necessidade de formar especialistas e técnicos de diversos níveis para atender à demanda, imprimiram uma nova perspectiva para a formação profissional. Como conseqüência, em 1978 o governo deu início à política de transformar algumas escolas técnicas em CEFETs, tendo por objetivos: a) ministrar ensino de graduação e pósgraduação, com vistas à formação de professores e especialistas para o ensino de segundo grau e formar tecnólogos; b) ministrar ensino de segundo grau, com vistas à formação de auxiliares e técnicos industriais; c) promover cursos de extensão, aperfeiçoamento e especialização, objetivando a atualização profissional na área industrial; d) realizar pesquisas na área técnica industrial, estimulando atividades criadoras e estendendo seus benefícios à comunidade, mediante a oferta de cursos e serviços (BRASIL, 1978).

Contudo, o duplo papel das escolas federais e dos CEFETs, de preparar os estudantes para o mundo do trabalho e para seguir os estudos em nível universitário, estaria contribuindo para diminuir as oportunidades às novas ocupações e promovendo o distanciamento progressivo entre o que as escolas técnicas ofertam e as preocupações de trabalhadores e de empresários, no tocante à formação profissional, instalando um dilema:

Se por um lado, essa nova função social - a de permitir o ingresso à universidade de indivíduos que não tiveram acesso a boas escolas de nível médio - pode ser considerada positiva, por outro, não estaria prejudicando sua função maior, que é a de formar técnicos de nível médio para os setores produtivos? (KIRSCHNER, 1993, p. 16).
Um dos principais problemas causados por esse dilema é a falta de respaldo das instituições públicas de ensino técnico-profissional, para a manutenção de seus altos gastos (KIRSCHNER, 1993, p. 15). Esse é um dos argumentos utilizados por empresários e políticos para subsidiar o discurso de que essas escolas federais e os CEFETs não atendem à sua função social primordial e que estariam voltadas para as elites, formando profissionais que, em grande parte, não chegam à ingressar no mercado de trabalho.

Mesmo admitindo os méritos das iniciativas desse período histórico (1930-1990) no campo do ensino médio, Nosella (2002) analisa que elas serviram mais para disfarçar, pela equivalência burocrática, a dicotomia entre as modalidades propedêutica e profissionalizante de ensino e, pretensamente, atender às aspirações dos trabalhadores por um maior nível de escolaridade e uma melhor formação profissional. Segundo ele, a política educacional

democratizou a clientela escolar mas deformou o método rebaixando a qualidade; ensinou ao povo o caminho da escola, porém não lhe deu uma verdadeira escola. Criou pobres cursos supletivos, cursos noturnos de 'faz-deconta', faculdades de beira de estrada, quatro ou até cinco turnos diários, superlotação de salas, má formação profissional, [...] tudo para 'cicatrizar' a dolorosíssima ferida de uma sociedade desigual, que para uns oferece a escola, para outros 'faz de conta' que oferece. (NOSELLA, 2002, p. 179).

\section{Educação profissional no Brasil: contexto atual}

Em nível internacional, a problemática 
da formação profissional de nível médio tem sido tratada de três formas básicas. Primeiro, como um sistema que se caracteriza por abrigar dois processos de formação independentes, não equivalentes: um que prepara o indivíduo para prosseguir os estudos em nível mais elevado e, outro, que prepara para ingressar no mundo do trabalho ao término do curso realizado, ou seja, possui caráter de terminalidade; segundo, como um sistema que oferece uma grande variedade de cursos, sendo que todos eles permitem avançar a um nível mais elevado de ensino; terceiro, como um sistema que propõe uma educação geral com ênfase na ciência e na tecnologia e uma educação profissional complementar.

Tendo esses eixos como referência, alguns consensos no tocante à política educacional estão-se ampliando. Primeiro, juntamente com a ciência e a tecnologia, a educação está incluída na pauta das políticas de Estado, considerada como importante fator para atender aos novos padrões de desenvolvimento; segundo, vem sendo compreendida como indispensável no processo para tornar as sociedades mais integradas e solidárias; terceiro, a aquisição e o domínio de conhecimentos científicos e habilidades cognitivas são condições necessárias para que todo sujeito seja capaz de selecionar e de assimilar as informações que considere relevantes para seu cotidiano de vida; quarto, a informação, o conhecimento e a internalização de valores éticos e morais são condições essenciais para o exercício da cidadania em sociedades plurais, cambiantes e cada vez mais complexas. (AMÂNCIO FILHO, 1997, p. 17).

Com relação aos rumos da educação profissional, no Brasil o movimento educacional mais recente tem sido no sentido de se aproximar mais dessa terceira forma, ao instituir um arcabouço legal visando a romper "com um modelo que preconizava a solução conciliatória entre os objetivos de preparar para o prosseguimento de estudos e a formação para o trabalho" (BERGER FILHO, 1999, p. 91), configurando uma educação profissional complementar ao ensino médio, ao mesmo tempo terminal e propedêutico.

Obedecendo ao disposto no Decreto $\mathrm{n}^{\circ}$ 5.154 (BRASIL, 2004), as escolas voltaram a oferecer a educação profissional e o ensino médio, de forma integrada, utilizando a mesma infra-estrutura, no mesmo turno/ escola com os mesmos professores. $\mathrm{O}$ Decreto visou a normatizar uma situação já observada na prática pedagógica cotidiana, ainda que sem o objetivo de terminalidade, com os estudantes tendo como expectativa o acesso a novos níveis de aprendizagem, não contemplando, porém, aspectos importantes para superar a dualidade que marca o ensino médio.

Conselho Nacional de Educação (1999), por meio das Diretrizes Curriculares Nacionais para a Educação Profissional de Nível Técnico, determinou a organização desta em vinte áreas profissionais: Agropecuária, Artes, Comércio, Comunicação, Construção Civil, Design, Geomática, Gestão, Imagem Pessoal, Indústria, Informática, Lazer e Desenvolvimento Social, Meio Ambiente, Mineração, Química, Recursos Pesqueiros, Saúde, Telecomunicações, Transportes e Turismo e Hospitalidade.

Para a construção dos currículos, o Ministério da Educação e o Conselho Nacional de Educação definiram que as matrizes de referência seriam formuladas e di- 
vulgadas pelo MEC na forma de referenciais curriculares, destinados a subsidiar as escolas na elaboração dos currículos e no planejamento dos cursos. Com essa intenção, foram publicados, no ano de 2000, 21 volumes contendo os Referenciais Curriculares Nacionais de Nível Técnico ${ }^{3}$.

Contudo, no que se refere à área da saúde, dada a diversidade e multiplicidade de saberes, de conhecimentos e de práticas que a conformam, constatou-se ser praticamente inviável aplicar à educação de nível técnico em saúde um processo de trabalho único e comum, levando em conta os Referenciais Curriculares Nacionais direcionados para essa área (BRASIL, 2000). Assim, são preconizadas para a saúde as seguintes subáreas: Biodiagnóstico, Enfermagem, Estética, Farmácia, Hemoterapia, Nutrição e Dietética, Radiologia e Diagnóstico por Imagem, Reabilitação, Saúde Bucal, Saúde e Segurança no Trabalho, Saúde Visual e Vigilância Sanitária.

No âmbito da saúde, o desafio posto pela realidade atual é o de adequar a incorporação tecnológica à estrutura de necessidades da área da saúde, pois não existem no mundo, e muito menos num país como o Brasil, recursos financeiros suficientes para suportar a lógica dos diagnósticos e exames complementares, baseados na tecnologia dos equipamentos de custo altíssimo e de rápida obsolescência. Urge que o papel do hospital seja redefinido na organização da atenção, mediante a valorização da atenção ambulatorial e domiciliar, da articulação da demanda espontânea a uma oferta organizada de serviços e da utilização do saber epidemiológico e social na realização das práticas de saúde. (BRASIL, 2000, p. 13).

Se inovações tecnológicas e de organização do trabalho vêm ocorrendo com maior intensidade na área industrial, é certo também que o setor de serviços não se encontra alheio às mudanças. No setor saúde é possível verificar sinais que atestam esse movimento, tais como: a) alta taxa de incorporação tecnológica; b) índices elevados de obsolescência tecnológica; c) aumento nos níveis de escolaridade dos trabalhadores; d) reivindicação por educação permanente para os trabalhadores; e) necessidade de novas qualificações profissionais; f) diminuição da remuneração; g) precarização dos vínculos de trabalho, com rotatividade de empregos. Ao mesmo tempo, amplia-se o debate sobre implementar medidas que resultem na humanização do atendimento, na promoção da saúde, na saúde da família e na internação domiciliar.

Observa-se que a sistemática que rege a aprendizagem no âmbito da saúde não deve mais se restringir à formação convencional, posto que se exige desse novo trabalhador da saúde mentalidade condizente com as transformações que ocorrem no mundo contemporâneo, com destaque para as que acontecem no interior do processo de trabalho. Entretanto, a dinâmica ensino/aprendizagem está, ainda, comprometida pelas próprias características das tendências curriculares:

Pensar os currículos voltados à formação técnica em saúde significa ter como premissa que as práticas curriculares são marcadas tanto pela historicidade da construção do próprio

${ }^{3}$ Um volume corresponde à Introdução ao tema e, os demais, a cada área profissional. 
conhecimento, como pelo pensamento hegemônico no mundo do trabaIho. Ou seja, trata-se de um processo conflituoso e contraditório, em que as exigências de uma formação humanista e crítica entram em constante choque com as exigências pragmáticas e objetivas do conhecimento definido pela divisão social do trabalho posta pelo capitalismo. (PEREIRA, 2004, p. 129).

Ponto a salientar é que, hoje, no Brasil, apesar de existirem escolas técnicas que buscam formar profissionais capazes de compreender e de enfrentar as mudanças presentes e futuras, persiste um ensino de concepção taylorista, que objetiva atender a necessidades pontuais e imediatas do mundo do trabalho. Com isso, continua a existir uma miríade de cursos de atualização, reciclagem, aperfeiçoamento, que servem para escamotear uma política de viés capitalista que prepara, rapidamente e a baixo custo, o profissional necessário para "consumo imediato".

\section{Considerações}

As iniciativas constituídas ao longo do tempo para oferecer uma educação técnica de nível médio em nosso país trazem presente o conceito de terminalidade, mesmo que de maneira subjacente, tendo como intenção possibilitar àqueles que concluem esse nível de ensino o exercício imediato de uma ocupação. Nesse entendimento, a formação profissional possibilitaria vencer a frustração de uma parcela de jovens egressos do ensino médio que, sem nenhuma habilitação profissional, têm como alternativa o caminho, inacessível para um enorme contingente deles, dos cursos superiores (CUNHA, 1977).
A maior causa de frustração dos candidatos não admitidos no ensino superior reside na ausência de uma ocupação útil numa idade em que se tornam absorventes as preocupações com o futuro. Só tardiamente, quando não se inclui na exceção dos egressos de cursos técnicos, o jovem descobre que a escola não the deu sequer a tão apregoada cultura geral, e apenas o adestrou para um vestibular em que o êxito é em função do número de vagas oferecidas à disputa. (BRASIL, 1971).

Ainda que enfatize a importância da formação profissional, o texto citado contém uma explicação no mínimo simplista e, mesmo, tendenciosa da realidade, ao debitar a procura pelo ensino superior a alguma deficiência do ensino médio, desconsiderando o fato de que essa procura é, também, impulsionada por uma importante variável, que é a valorização desses cursos como requisito de ascensão social. $\bigcirc$ fato de egressos do ensino técnico de nível médio conseguirem, além do domínio de determinada técnica, acumular conhecimentos propedêuticos suficientes para que, nos exames para ingresso no nível universitário, concorram em igualdade de condições com candidatos que cursaram apenas as disciplinas da chamada "formação geral", reforça o entendimento de que é necessário integrar a formação propedêutica e a técnica.

Também é preciso ter em conta que superar a frustração dos formados inclui vencer a dificuldade de ocupar um posto de trabalho imediatamente após a conclusão do curso. Infelizmente, qualquer curso, seja de nível médio, graduação ou pós-graduação, não traz em si a chave para essa vitória, em ra- 
zão, principalmente, do descompasso que se observa entre a esfera que forma (educação) e a que emprega (mercado), ocasionado por um mútuo desconhecimento de interesses, de necessidades e de distanciamento para desenvolverem, em parceria, ações conjuntas.

No Brasil, a política de educação profissional está baseada na suposição de que o crescimento dos setores industrial e de serviços, verificado a partir da segunda metade do século $X X$, promoveu e ainda promove um aumento da demanda de técnicos de nível médio - argumento refutável se analisarmos o quantitativo de vagas para técnicos oferecidas por empresas e a quantidade de currículos que se acumulam nos Conselhos Profissionais que oferecem "bancos de empregos". Ademais, o excesso de oferta de trabalhadores qualificados favorece o surgimento de exigências mais rigorosas para o preenchimento de vagas e negociações que resultam em diminuição de salários (GOUVEIA; HAVIGHURST, 1969, p. 194).

Analisando o processo de formulação da Lei no 5.692 (BRASIL, 1971), por exemplo, verifica-se que sua discussão teve início com as mudanças ocorridas com o golpe militar de 1964. A política econômica adotada a partir de então, torna cada vez mais difícil a possibilidade de ascensão social por via nãoeducacional, na medida em que dificulta novos empreendimentos no comércio e na indústria. Esse fator provocou uma verdadeira corrida pelo ensino superior e, apesar do aumento do número de vagas implementado nesse nível de ensino, a demanda permanece significativamente maior do que a oferta.

A ênfase na terminalidade do ensino médio e as conseqüentes políticas de profissionalização têm, desde a sua gênese, uma nova e importante função no que diz respeito à manutenção da hierarquia social e à governabilidade: conter a demanda ao ensino de nível superior. Na saúde, por exemplo, até a década de 90, um grande contingente de trabalhadores de nível elementar e médio obtinha habilitação para o exercício profissional após o ingresso nos serviços de saúde. Hoje, porém, após regulamentadas as profissões de nível técnico em saúde, exige-se a comprovação escolar da habilitação, o que fez aumentar a demanda institucional e a necessidade social pela formação de quadros técnicos a serem absorvidos pelo sistema de saúde, o que diferencia o setor de outras áreas, nas quais o número de novos postos de trabalho para os habilitados é menor do que foi no passado.

A questão do dilema formativo nos cursos de nível técnico encontra, então, na área da saúde, locus privilegiado. Além de todas as contradições presentes na educação profissional, a área acumula, uma tradição de carreira, de identidades profissionais transitórias, de variados itinerários formativos, de hierarquia no trabalho em equipe e na formação em serviço que a torna a antítese da política de terminalidade no ensino médio.

Finalmente, o desafio de construir, de fato e de direito, um sistema de saúde democrático e participativo, obriga a refletir e a compartilhar intervenções no processo de formação profissional, não só para preparar indivíduos aptos a ingressarem no mundo do trabalho em saúde, conscientes de sua responsabilidade técnica e social, mas, fundamentalmente, formar homens e mulheres cientes de seus direitos e deveres na construção de uma sociedade menos desigual. 


\section{Referências}

AMÂNCIO FILHO, A. Cenários e situações da formação em saúde no Brasil. Boletim Técnico do Senac, Rio de Janeiro, v. 23, n. 3, p.11-25, 1997.

BERGER FILHO, R. L. Educação profissional no Brasil: novos rumos. Revista Iberoamericana de Educación, Madrid, v. 20, p. 87-105, 1999.

BRASIL. Decreto n 7.566, de 23 de setembro de 1909. Legislação, Brasília, DF, [200?]. Disponível em: <https://legislacao.planalto.gov.br>. Acesso em: 26 abr. 2005.

. Lei $n^{\circ}$. 4.024, de 20 de dezembro de 1961. Fixa as diretrizes e bases da educação nacional. Disponível em: <http://www.planalto.gov.br/ccivil 03/leis/ 14024.htm>. Acesso em: 5 jun. 2007.

Lei $n^{\circ}$. 5.692, de 11 de agosto de 1971. Fixa diretrizes e bases para o ensino $\overline{\text { de } 1^{\circ}}$ e $2^{\circ}$ graus, e dá outras providências. Disponível em: <http://www.planalto.gov.br/ ccivil/leis/L5692 >. Acesso em: 5 jun. 2007.

Lei 6.545, de 30 de junho de 1978. Dispõe sobre a transformação das Escolas Técnicas Federais de Minas Gerais, do Paraná e Celso Suckow da Fonseca em Centros Federais de Educação Tecnológica e dá outras providências. Disponível em: <http://www.planalto.gov.br/CCIVIL_03/LEIS/L6545.htm>. Acesso em: 16 ago. 2006.

Ministério da Educação. Educação profissional: referenciais curriculares nacionais da educação profissional de nível técnico/área profissional: saúde. Brasília, DF, 2000.

CAMPOS, F. Exposição de motivos, apresentada ao Chefe do Governo Provisório, encaminhando o Projeto de Reforma do ensino Superior. In: BRASIL. Ministério da Educação e Saúde Pública. Decretos nos 19.850, 19.851 e 19.852, de 11 de abril de 1931. Rio de Janeiro: Imprensa Nacional, 1931.

CONSELHO FEDERAL DE EDUCAÇÃO (Brasil). Relatório do Grupo de Trabalho instituído pelo decreto $n^{\circ}$. 66.600, de 20 de maio de 1970. In: Ensino de $1^{\circ} \mathrm{e}$ $2^{\circ}$ graus. Rio de Janeiro, 1971.

CONSELHO NACIONAL DE EDUCAÇÃO (Brasil). Câmara de Educação Básica. Resolução n 4/99. Disponível em: <http://portal.mec.gov.br/cne/arquivos/pdf/ CEB04991.pdf>. Acesso em: 05 jun. 2006.

CUNHA, L. A. O ensino industrial-manufatureiro no Brasil. Revista Brasileira de Educação, São Paulo, v.14, p. 89-107, maio/ago. 2000.

Política educacional no Brasil: a profissionalização no Ensino Médio. Rio de Janeiro: Livraria Eldorado Tijuca Ltda., 1977.

FONTES, L. B. Formação profissional \& produtividade do desempenho humano. Rio de Janeiro: SENAI/DN, 1985. 
GARCIA, N. M. D.; LIMA FILHO, D. L. Politecnia ou educação tecnológica: desafios ao ensino médio e à educação profissional. In: REUNIÃO ANUAL DA ANPED, 27., 2004, Caxambu. Trabalhos apresentados... Caxambu, MG, 2004.

GOUVEIA, A. J.; HAVIGHURST, R. J. Ensino médio e desenvolvimento. São Paulo: Melhoramentos, 1969.

KIRSCHNER, T. C. Modernização tecnológica e formação técnico-profissional no Brasil: impasses e desafios. Rio de Janeiro: IPEA, 1993.

KUENZER, A. Z. Ensino médio: construindo uma proposta para os que vivem do trabalho. São Paulo: Cortez, 2001.

O trabalho como princípio educativo. Cadernos de Pesquisa: revista da

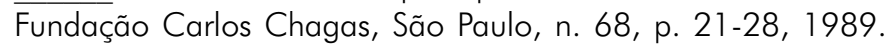

LIMA, J. C. F. Tecnologias e a educação do trabalhador em saúde. In: FIOCRUZ. Formação de pessoal de nível médio para a saúde: desafios e perspectivas. Rio de Janeiro, 1996.

MACHADO, L. R. S. Politecnia, escola unitária e trabalho. São Paulo: Cortez, 1989. MANFREDI, S. M. Educação profissional no Brasil. São Paulo: Cortez, 2002.

NOSELLA, P. A escola brasileira no final de século: um balanço. In: FRIGOTTO, G. (Org.). Educação e crise do trabalho: perspectivas de final de século. 6. ed. Petrópolis: Vozes, 2002.

OLIVEIRA, D. Profissionalização do ensino de $2^{\circ}$ grau. Rio de Janeiro: UERJ, 1981.

OLIVEIRA, R. Empresariado industrial e a educação profissional brasileira. Educação e Pesquisa, São Paulo, v. 29, n. 2, p. 249-263, jul./dez. 2003.

PEREIRA, I. B. Tendências curriculares nas escolas de formação técnica para o SUS. Trabalho, Educação e Saúde, Rio de Janeiro, v.2, n.1, p.121-134, mar. 2004.

SALGADO, M. U. C. O novo paradigma da organização do trabalho e a formação profissional na área da saúde. In: AMÂNCIO FILHO, A.; MOREIRA, M. C. G. B. (Org.). Saúde, trabalho e formação profissional. Rio de Janeiro: Fiocruz, 1997.

SAVIANI, D. O choque teórico da politecnia. Trabalho, Educação e Saúde, Rio de Janeiro, v.1, n. 1, p.134-151, mar. 2003.

SUCUPIRA, N. Aspectos da organização e funcionamento da educação brasileira. Brasília, DF: MEC, 1974.

Recebido em: 29/08/2006

Aceito para publicação em: 18/04/2007 